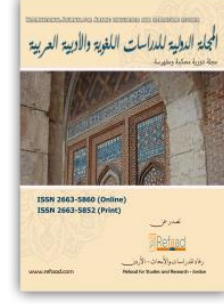

\title{
الصراع الثقافي في شعر المتنبي \\ مدح سيف الدولة وعضد الدولة نموذجًا
}

\author{
خيرية قرتاي \\ باحثة من تركيا- طالبة دكتوراه في الجامعة الأردنية- الأردن \\ eledven@gmail.com
}

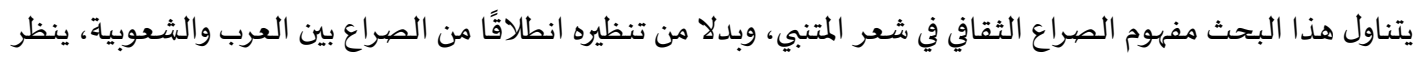

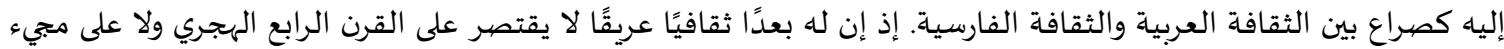

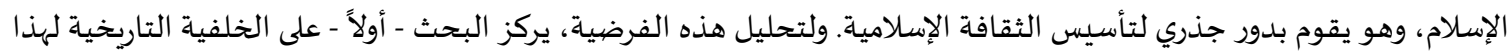

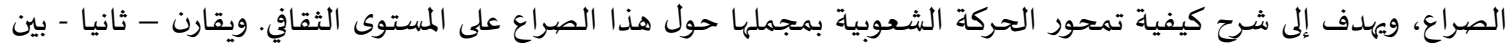

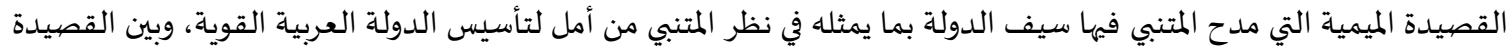

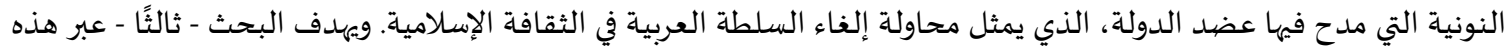

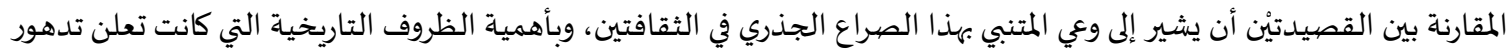
الدولة العباسية في القرن الرابع الهجري، وأثر ذلك في تشكل هذا الوعي وتجليه شعريًا وسياسيًا. الكلمات المفتاحية: الصراع الثقافي في العصر العباسي؛ العرب والشعوبية؛ السياسية وشعر المتنبي. (9) (1)

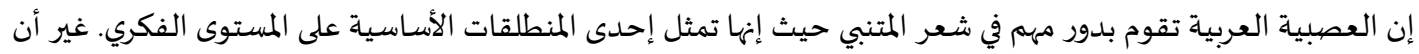

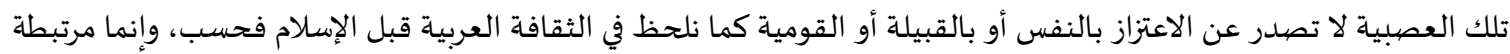

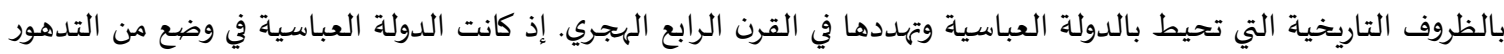

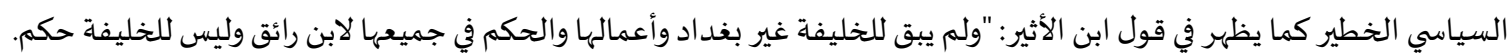

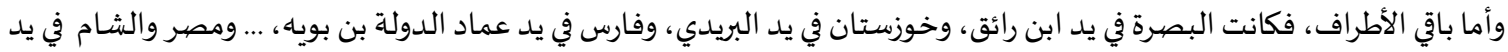

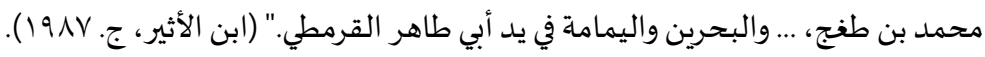

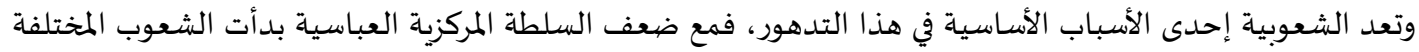

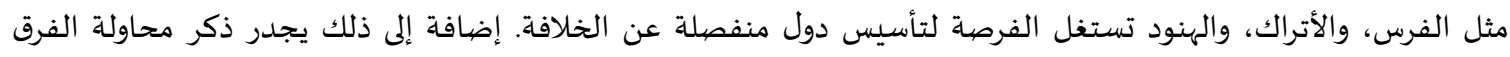

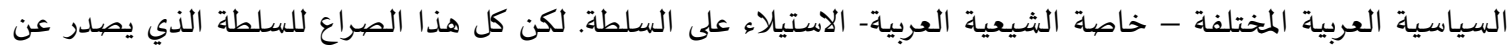

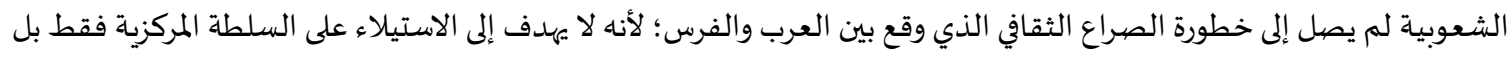

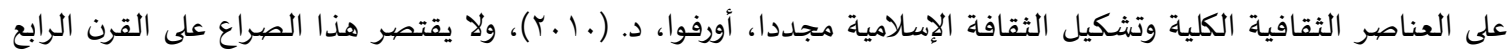

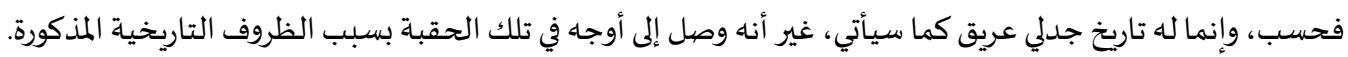

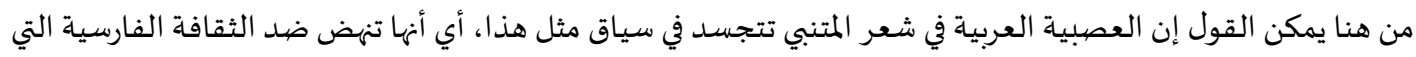

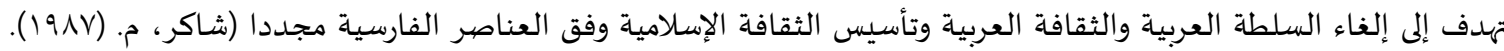

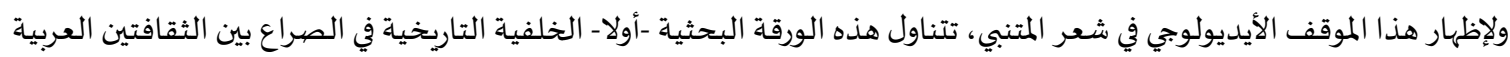
والفارسية وأسبابه، وتسعى لتوضيح كيفية تمحور الحركة الشعوبية بمجملها حول هذا الصراع على المستوى الثقافي. 
ثانيا تقارن الورقة البحثية بين مدح سيف الدولة الذي يمثل أمل تأسيس الدولة العربية القوية، ومدح عضد الدولة الذي يمثل محاولة إلغاء السلطة العربية في الثقافة الإسلامية. ولتأكيد هذا الموقف تتناول الورقة البحثية القصيدة الميمية (واحر قلباه

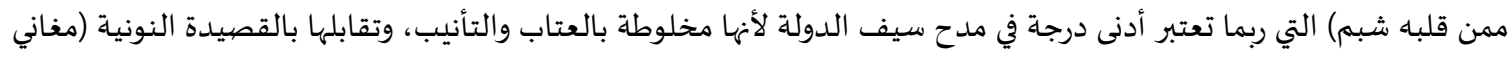

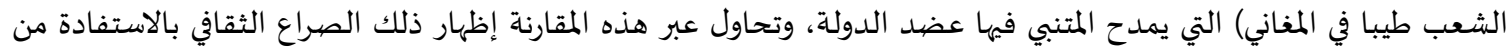
مقولات النقد الثقافي انطلاقا من بعض العناصر المنهجية مثل: التفكيكية والتناص، والحجاج على وجه الخصهوص.

\section{ا. الخلفية التاريخية: الصراع بين الثقافة العربية والفارسية} كما سبقت الإثـارة فإن الصراع السياسي والثقافي بين العرب والفرس يصنّف عادةً تحت مادة الشعوبية، وكذلك الصراع مع

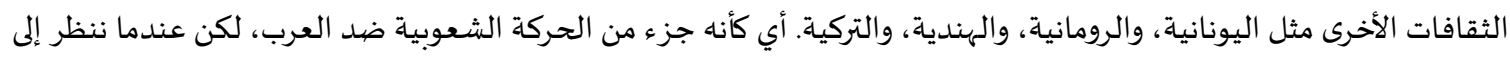

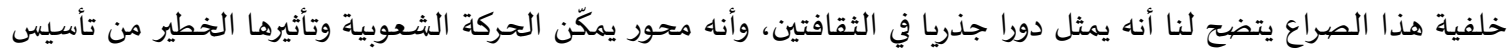

الثقافة الإسلامياة.

ويمكن إرجاع تاريخ هذا الصراع إلى ما قبل الميلاد أو إلى التاريخ الذي ألغت فيه الإمبراطورية الفارسية القديمة ثقافة ما بين الهرين. من الغريب أن هذا التاريخ سنة وجه ق.م هو تاريخ تأسيس الإمبراطورية الفارسية أيضا، بمعنى أنها تنهض لإلغاء ثقافة ما بين

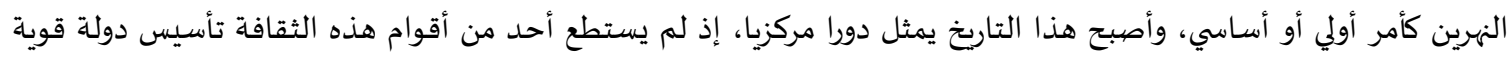

وتجميع الأقوام الأخرى حوله حتى مبيء الإسلام.

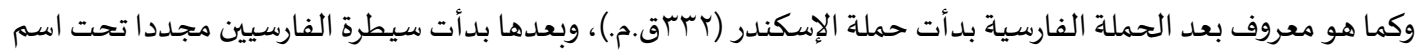

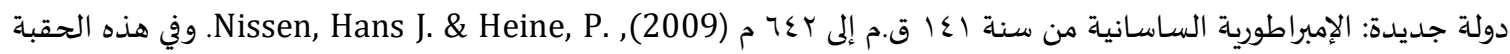

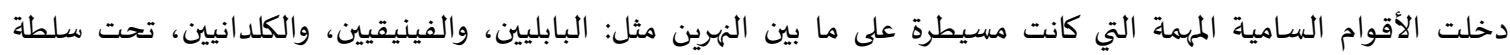
الفارسيين، واضمحلت هذه الأقوام التي قامت بدور مهم في تاريخ الإنسان تحت هذه السيطرة (Van De Mieerop, Marc 2016)' وبعد ذلك خاصة بداية من القرن الثالث الميلادي- نرى العرب -بين الساميين- كقوم مؤثر في ما بين النهرين مثل اللخميين ومملكة الحضر، إلا أنهم كانوا تحت سيطرة الفارسيين أيضا. وعلى الرغم من محاولتهم للتخلص من هذه السيطرة من حين إلى آخر إلا أنهم

بقوا على تلك الحال حتى الإسلام (Nissen, Hans J. \& Heine, P. ,2009).

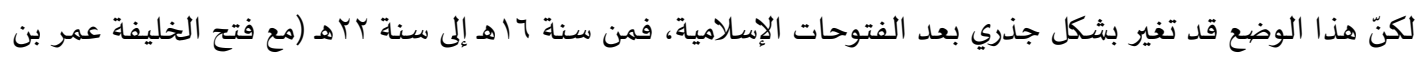

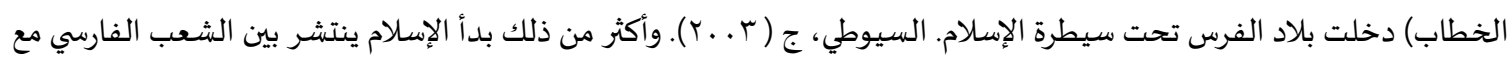
بداية الفتوحات، مع ذلك استمر ذلك الصراع القديم بصورة مختلفة، أي أنه لا يظهر كصراع بين الثقافتين إنما يظهر كصراع داع داخل الثقافة نفسها؛ وهي الثقافة الإسلامية، أي عندما اضطر الفرس إلى قبول سيطرة العرب حاولوا الاستيلاء على السلطة داخل أفق الثقافة الإسلامية سواء على المستوى السياسي أو الثقافي. على المستوى السياسي يجدر ذكر دعمهم للحركة الشيعية بأشكال مختلفة طوال العصري العباسي كما يظهر عبر الصراع إع بين

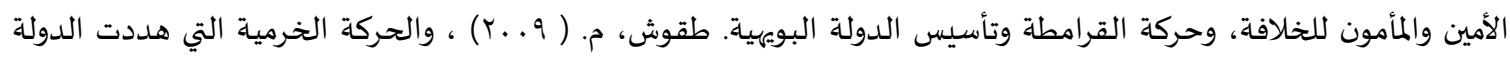

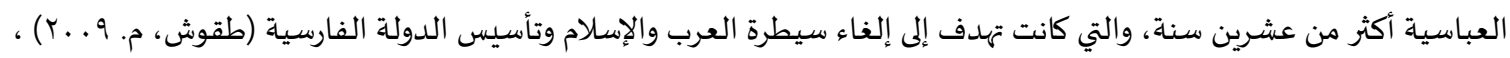

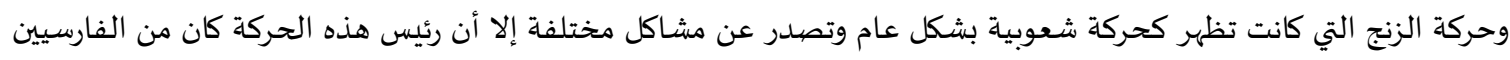

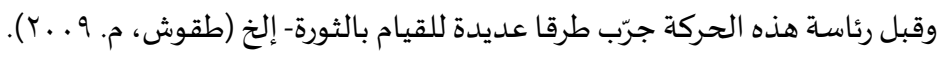

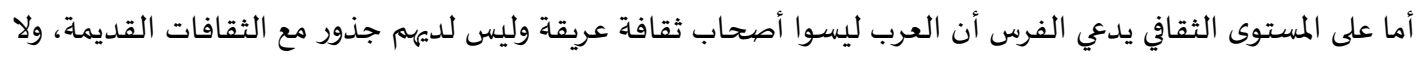

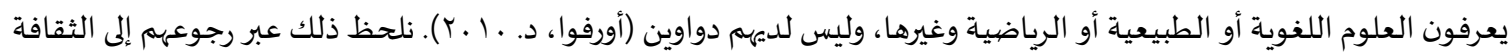
الفارسية القديمة لإثبات عراقة ثقافتهم. في هذا الصدد يمكن ذكر ترجمات ابن المقفع عن "الأدبيات السياسية الفارسية القديمة وتعريها مثل كتابه الأدب الكبير الذي شحنه بالحكم والأمثال ذات المدلول السياسي الاجتماعي وهناك رسالة الصحابة التي تعد بمثابة بيان سياسي دستوري يطرح

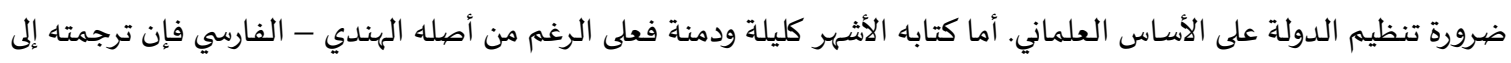

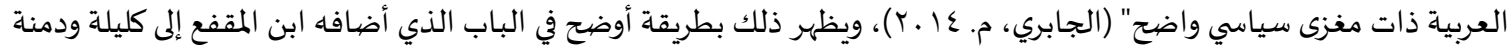

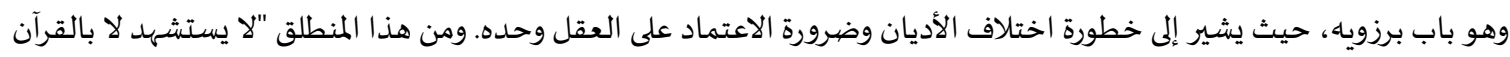

في ما يخص نجاح الفينيقيين والكلدانيين في العلوم -مثل علم الفضاء، والطب، والرياضيات، والسيمياء انظر إلى..Van De Mieerop, Marc (2016) 
ولا بالحديث ولا بأي عنصر آخر من الموروث الإسلامي، بل بالعكس يدعو صراحة إلى الأخذ من الموروث القديم السابق للإسلام"الجابري، م. ( ع ا.ب). غير أن ذلك السابق للإسلام يجب أن يُؤُخذ من الثقافة الفارسية والهندية وليس من الثقافة العربية القديمة ولا ثقافة ما بين النهرين.

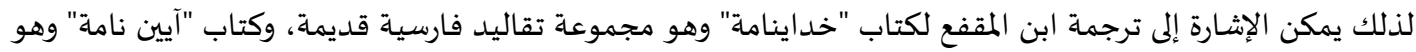

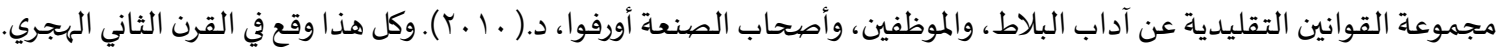

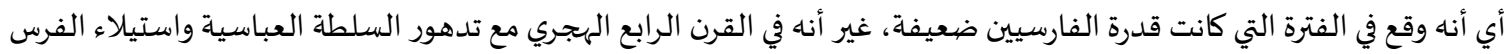

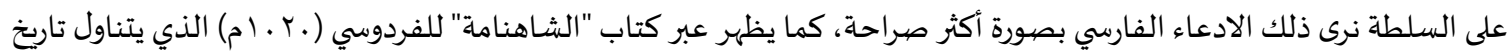

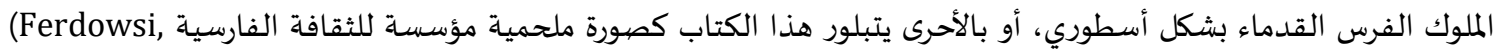

وبالتالي بدأت تتشكل الثقافة العربية الإسلامية تحت ظل هذه التحديات، لكنْ قبل أن نركز على ردود أفعالها يمكن الإشارة

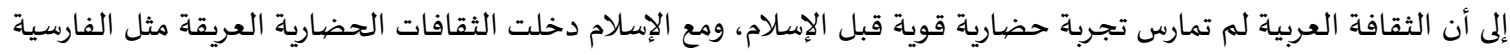

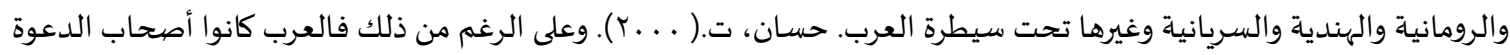

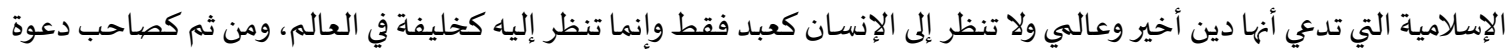

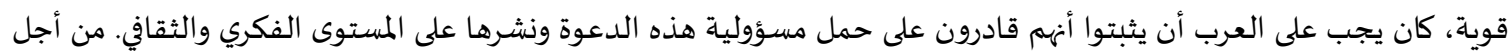

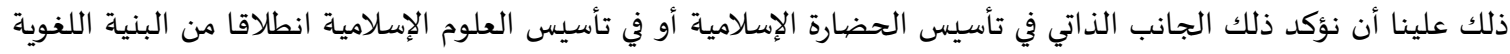

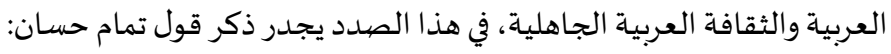

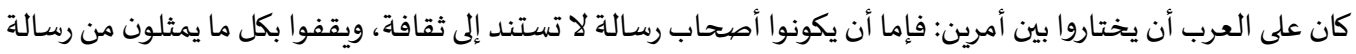

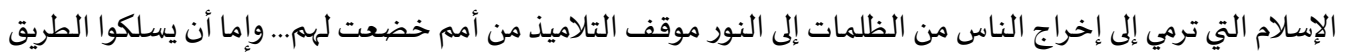

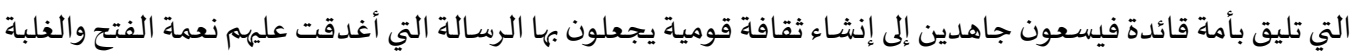

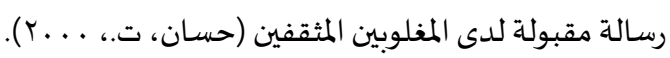

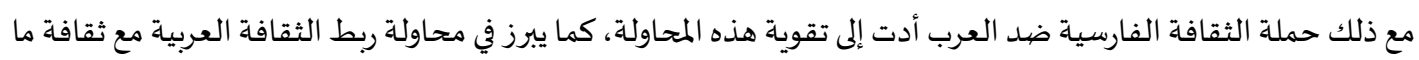

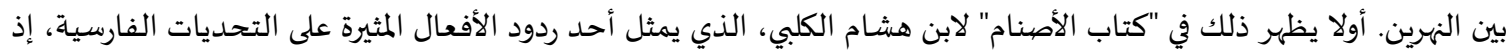

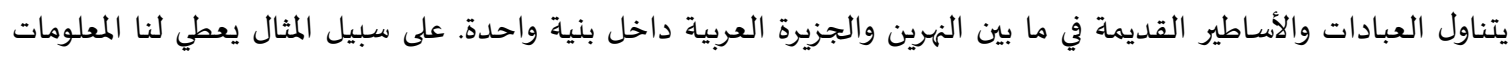

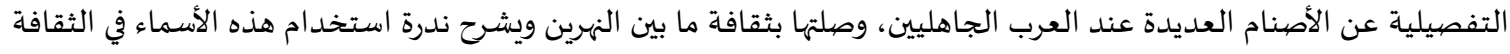

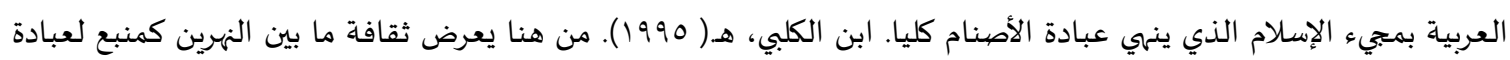

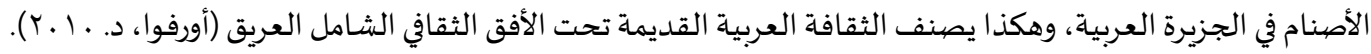

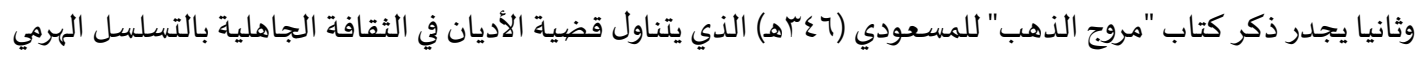

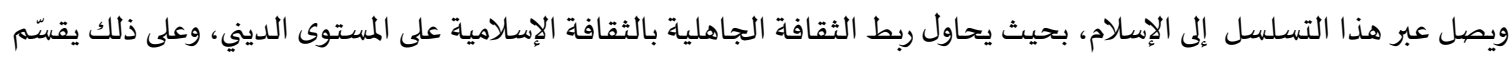

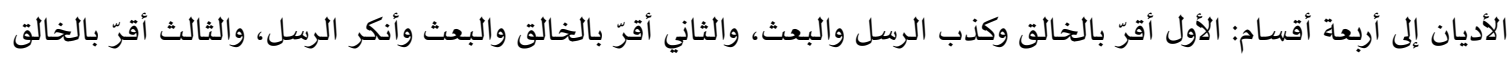

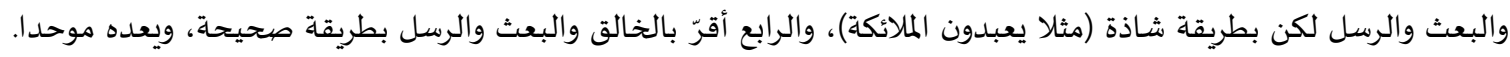

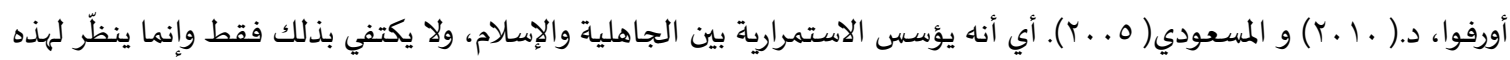

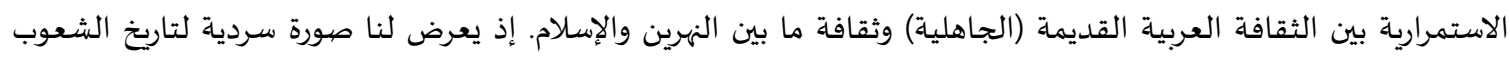

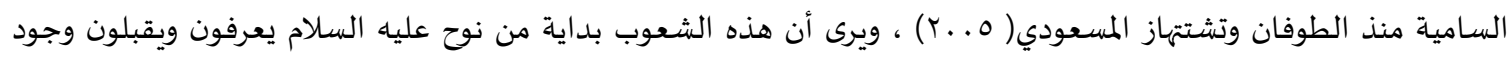

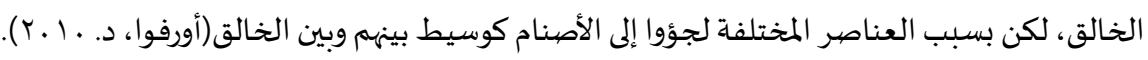

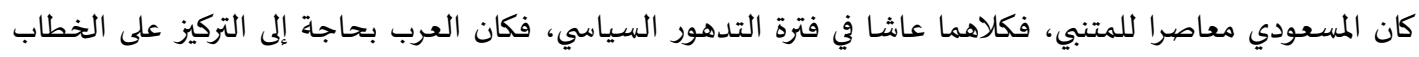

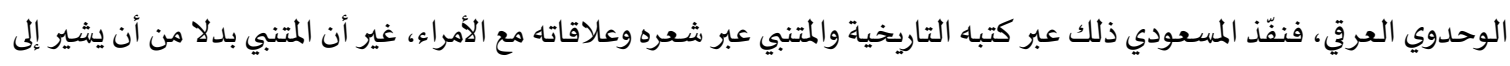

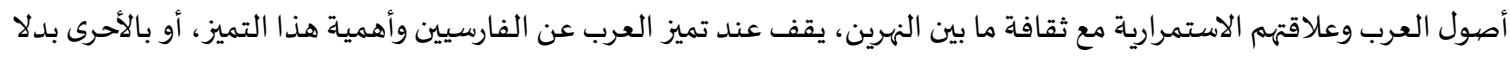

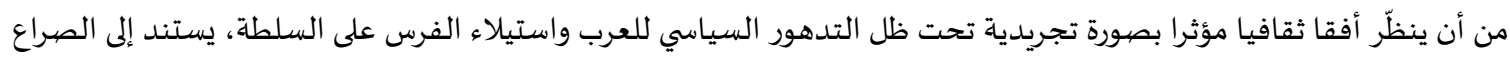
الحي سواء على مستوى التجربة الشعرية أو السياسية. 
r ا ب. ازدواجية المدح بين سيف الدولة وعضيد الدولة

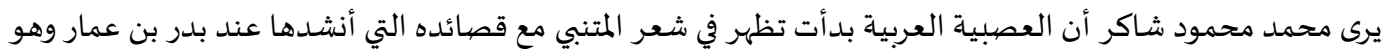

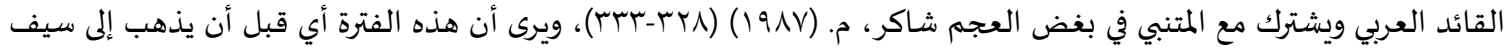

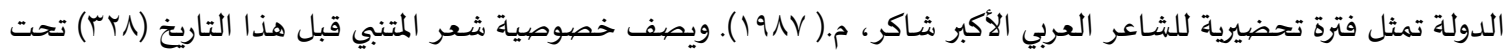

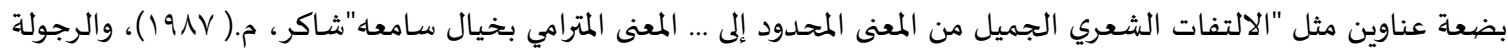

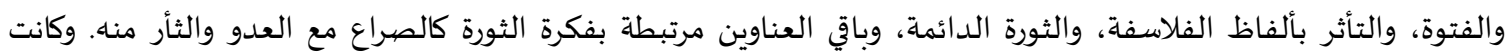

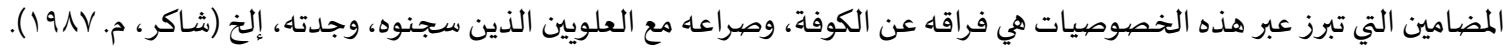

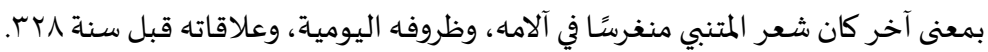

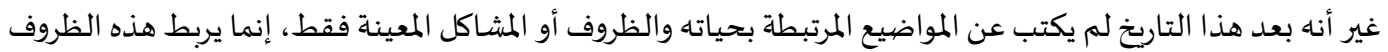

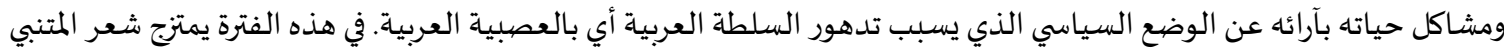

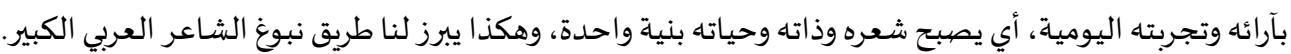
كأن هذا القائد العربي، بدر بن عمار، بسطوته، وقوته أيقظ أمل وحدة الدولة العربية الإسلامية في المتنبي كما يظهر في أول

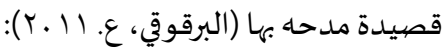

$$
\begin{aligned}
& \text { أمِ الخلقَ في شخص حي أعيدا } \\
& \text { كأنا نجوم لقينا سعودا }
\end{aligned}
$$

$$
\text { أحلما نرى، أم زمانا جديدا }
$$$$
\text { تجلى لنا فأضيأنا به }
$$

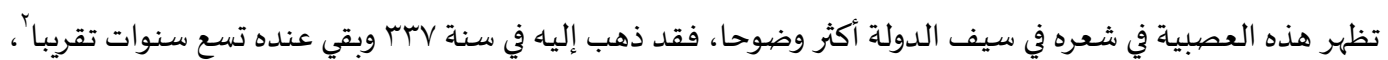

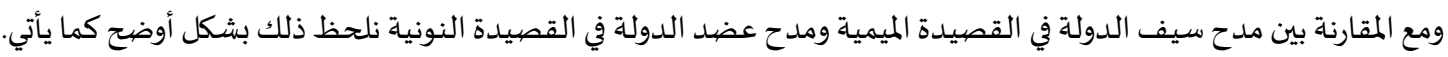

أ) مدح سيف الدولة والقصيدة الميمية

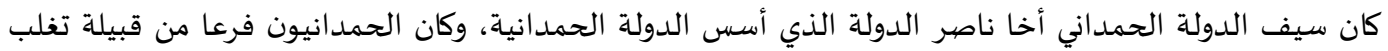

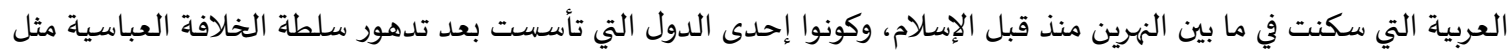

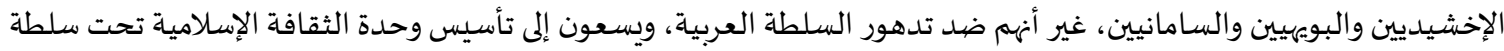

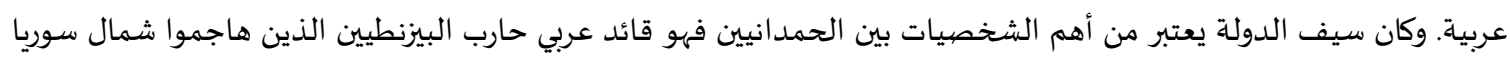

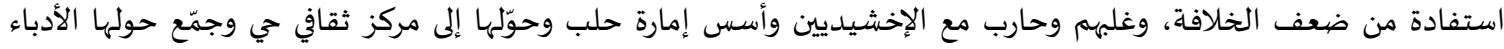

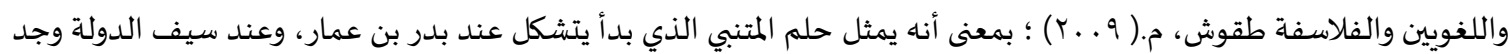

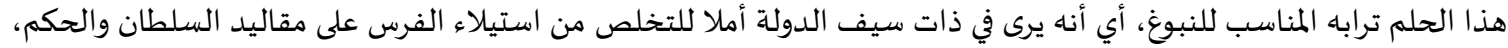

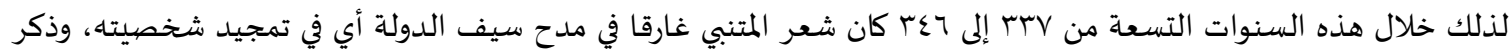

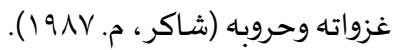

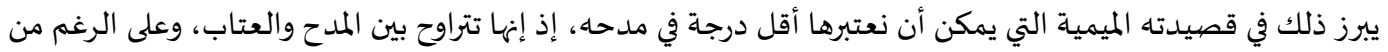

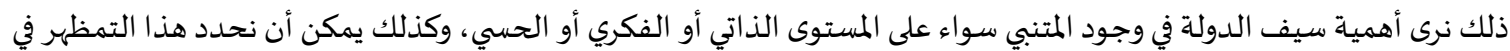
ثلاثة مستويات: أولاً: عتابه لسيف الدولة ينطلق من حبه: يبدأ المتنبي بالقصيدة ويعاتب سيف الدولة بسبب قلة اهتمامها به بين الشعراء الذين

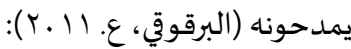

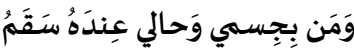

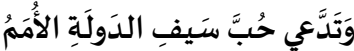

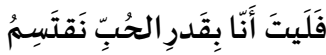

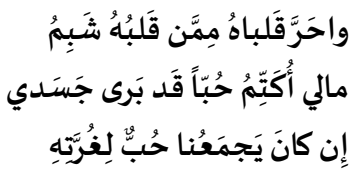

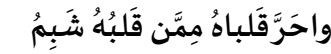

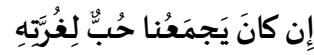


أي يشكو من احتراق قلبه حبا وهياما بسيف الدولة بارد القلب، وعلى الرغم من أن حب المتنبي تحول إلى مرض، إلا أن سيف الدولة

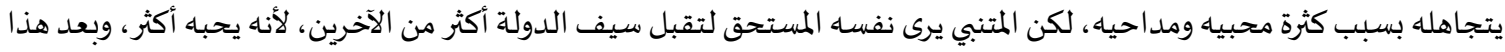

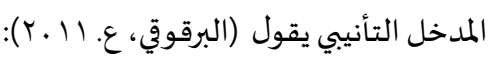

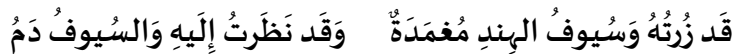

يؤكد المتنبي في هذا البيت أنه سيبقى عند سيف الدولة رغم غضببه وتأنيبه له، أو بالأحرى سيكون عنده في حالة السلام أو الحرب. يرجع إلى مفهوم السيف لتأسيس المعنى الدلالي الجديد، إذ يستخدم السيف في حالتين، الأولى عندما يكون السيف في غمدهده

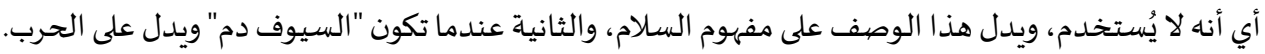

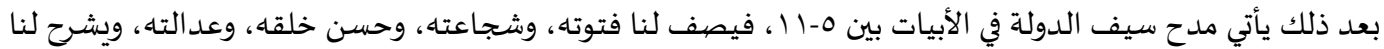

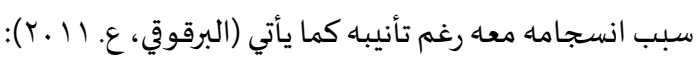

$$
\begin{aligned}
& \text { وَكَانَ أَحسَنَ ما في الأَحسَنِنِ الثِيَيَمُ }
\end{aligned}
$$

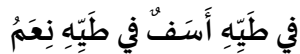

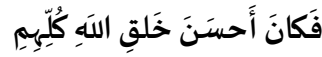

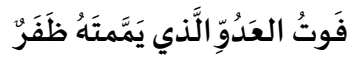

وفي القسم الأخير في القصيدة (الأبيات بين 7Y-YV) يرجع إلى الشكوى من أعدائه وجهدهم لإيجاد عيب في شخصية المتنبي،

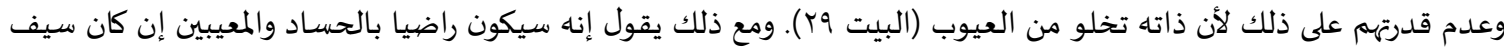

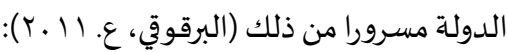

$$
\text { فَمَا لِجُرحِح إِذا أَرضهاكُمُ أَلَمُ }
$$

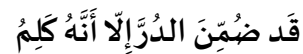

إن كانَ سَرَّكُمُ ما قالَ حاسِدُنا وينهي القصيدة بالبيت:

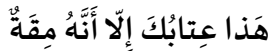

ومع هذا البيت الختامي يثبت أن عتابه يصدر عن محبته، بحيث "إن العتاب يجري بين المحبين"، ويحتج بالعلاقة بين الدر

والكلم لشرح العلاقة بين العتاب والمحبة، فللوصول إلى الدر نحتاج جرحا -من المعاني الاشتقاقية لكلم الجرح (ابن منظور، ج. د. د. ت) -

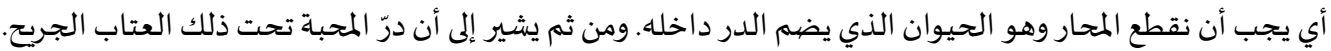

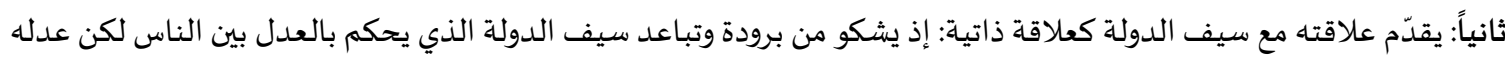

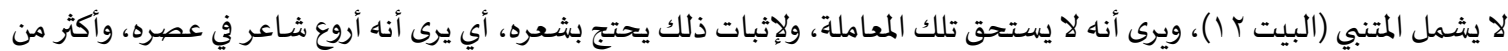

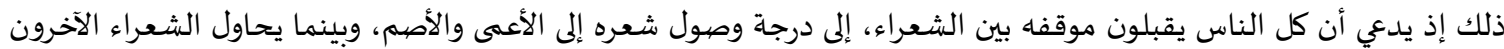

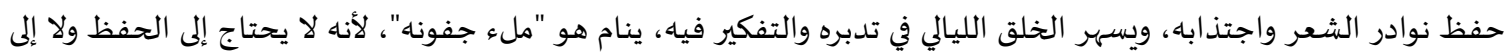

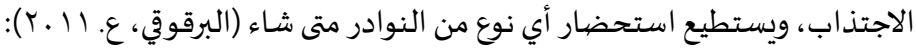

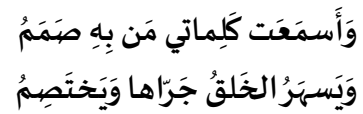

أَنا الَّذي نَظَرَ الأَعمى إلِى أَدَبي

أَنامُ مِلََ جُفوني عَنَ شَوارِدِدها

ولا يكتفي بالاعتزاز بشعره فقط، وإنما يعتز بشجاعته وفتوته. فيشبّه ذاته بالأسد ويهدد عدوه عبر هذا التشبياه (البيت

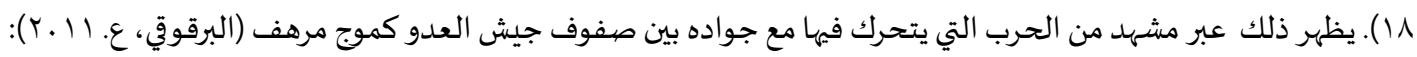

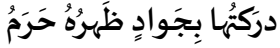

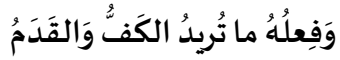

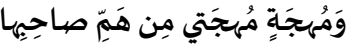

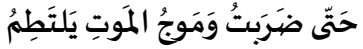

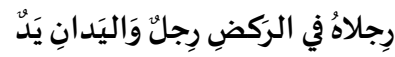

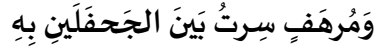

بمعنى أنه لا يدخل إلى الصراع على المستوى الفكري التجريدي فقط، وإنما يدخله بكل أجزائه: جسـده، وشعره، ودهائه،

$$
\text { والسيفُ والرُمحُ والقرطاسُ والقلمُ }
$$

فالخيلُ والليلُ والبيداء تعرفني 
غير أن هذه الوحدة في تجربته وتفكيره لن تصل إلى غايتها في تأسيس وحدة الثقافة الإسلامية تحت رئاسة العرب إلا مع سيف

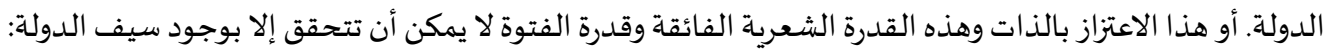

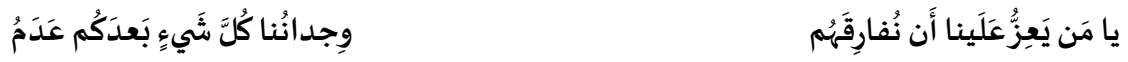

وهكذا تتسق ذات المتنبي بذات سيف الدولة جذريا، فشعره الذي يمثل أروع نوع، ودهاؤه، وشجاعتاه وفتوته التي تشبه قوة

الأسد تصبح لا شيء دون وجود سيف الدولة. وتجربته الشعرية تثبت ذلك أيضا؛ فهو لم يمدح أحدا غير سيف الدولة خلال السنوات التسعة التي بقي فهها عنده، بل إن كل أشعاره التي أنشدها تلك الفترة تقريبا مغروسة في مدح سيف الدولة بصيور عديدة

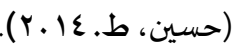

والبيت الذي يليه يؤكد هذه الصلة الذاتية التي تتمحور حول فكرة العصبية العبية بشكل أوضح، بحيث إن هذا الجانب

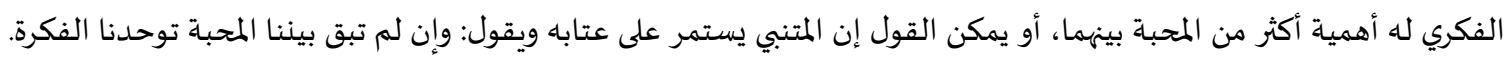

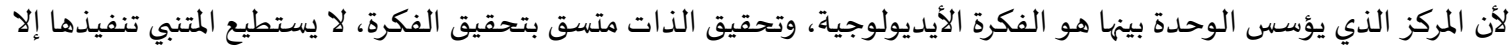

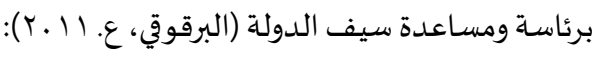

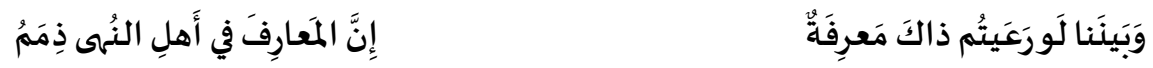

وثالثاً، يمكن أن نقف عند استخدام الضمائر في القصيدة، وعلاقتها بموفق المتنبي تجاه سيف الدولة. فنلحظ أن هناك ازدواجية في

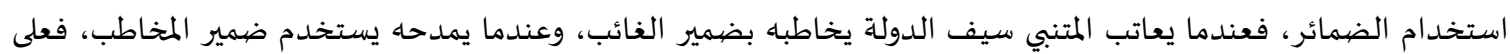

$$
\begin{aligned}
& \text { وَمَن بِجِسـي وَحَالي عِندَهُ سَقَمُمُ } \\
& \text { فَلَيَتَ أَنَّا بِقَدرِ الحُبِِّ نَقَتَسِِمُ }
\end{aligned}
$$$$
\text { وَكَانَ أَحسَنَ ما فِي الأَحسَنِنِ الشِيَهُ }
$$

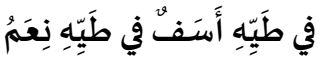

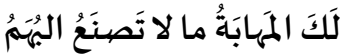

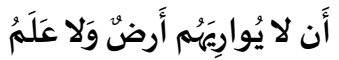

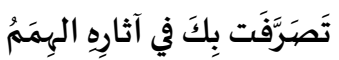

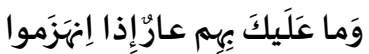

سبيل المثال في بداية القصيدة يعاتبه بضمير الغائب:

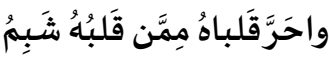

$$
\begin{aligned}
& \text { إِن كانَ يَجَمَعُنَا حُبِّن لِغُرَّتَّهِ }
\end{aligned}
$$

وفي الكلام عن حباء تجاهه يميل إلى ضمير المخاطب (في الأبيات ه-. ()):

$$
\text { فَكَانَ أَحسَنَ خَلقِ اللَهِ كُلِّهِهِ }
$$

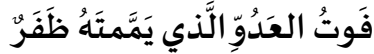

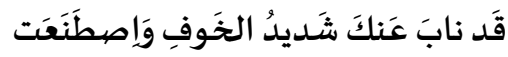

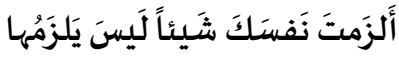

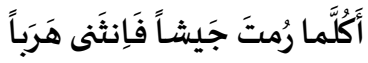

عَلَيكَ هَزْهُهُمْ فِي كُلِّ مُعتَرَكِ

واستمرت تلك الازدواجية في الأبيات التالية، غير أن ضمير المخاطب يستخدم أكثر من ضمير الغائب، في الحقيقة إن ضمير الغائب لا يستخدم في كل أبيات العتاب، بل يستخدم في الأبيات الأولى، وهذه الأبيات تمثل أشـد تأنيب في القصيدة.

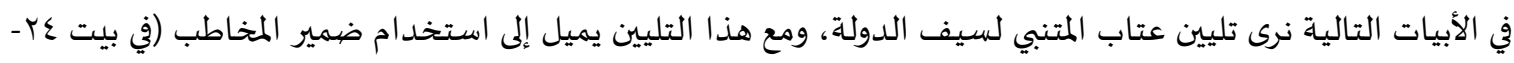

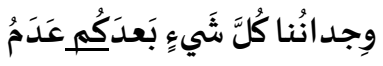

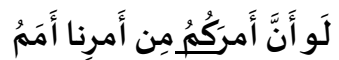

عبر هذا الاستخدام للضمائر يظهر أن المتنبي عندما يؤنب سيف الدولة يستخدم ضمير الغائب، وهكذا كأنها يبعد ذات المتنبي

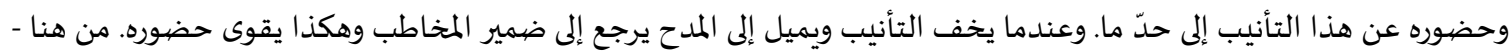

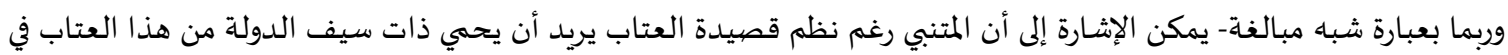
الوقت نفسـه. 
ب) مدح عضد الدولة والقصيدة النونية

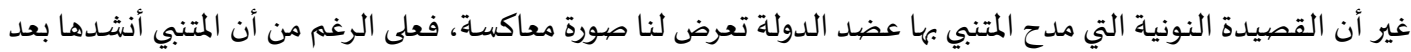

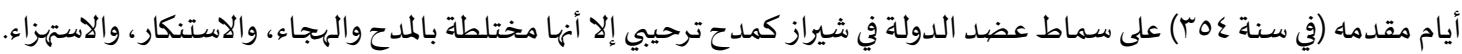

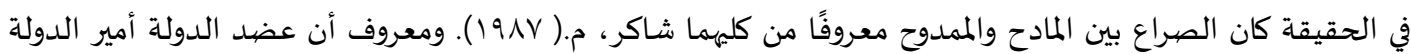

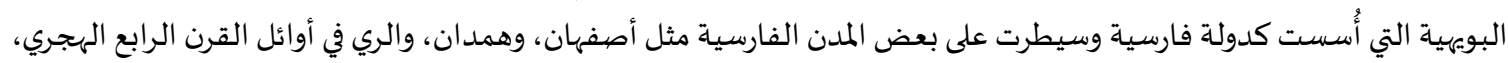
والتي بسطت هذه السيطرة على العراق، وعلى الخلافة في ما بعد (ضيف، ش. د.ت). أي أن عضد الدولة يمثل طموح الفرس في في وند

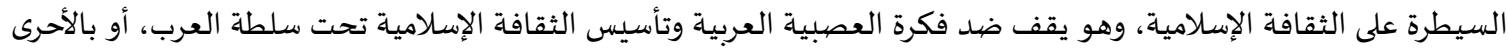

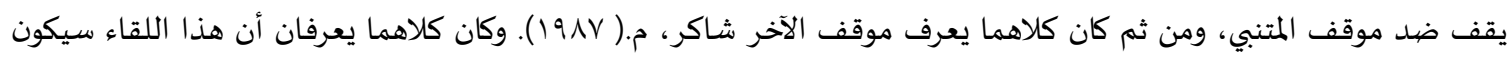

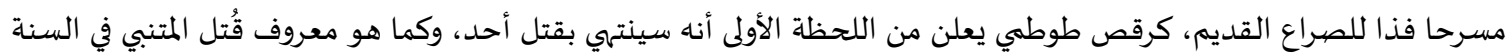
نفسها (ع هـهـ) بعد خروجاه من شيراز بقليل. يظهر هذا الرقص القاتل عبر حركة المد والجزر في القصيدة، بين المدحح والهجاء، القبول والاستنكار، التأييد والتهديد. ويمكن أن نركز على هذه الحركة الدلالية في مستويين: الأول هو ظهور هذا الصراع الدلالي بين شيراز ودمشق حيث يسيطر على ما يقارب نصف القصيدة (أول سبعة عشر بيتا)، إذ

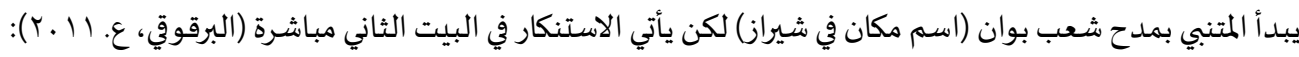

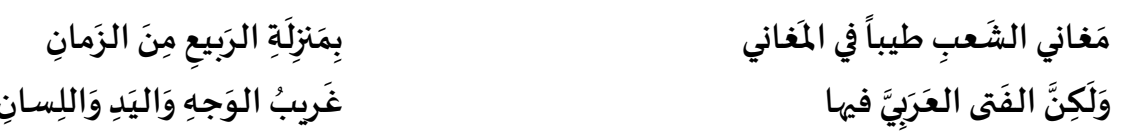

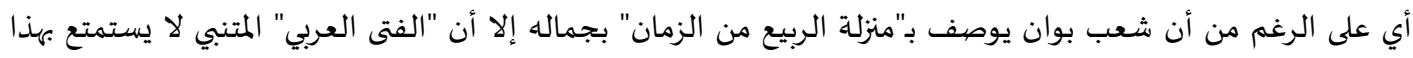

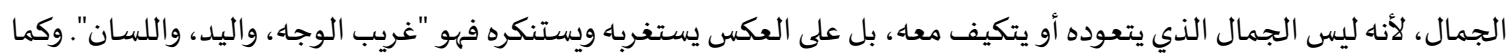

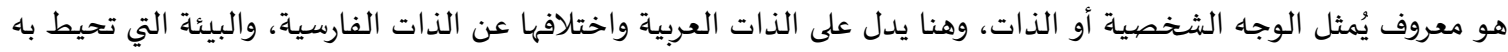

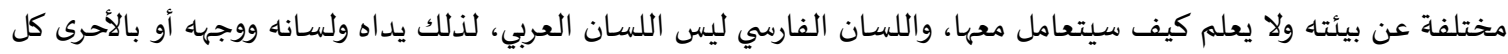

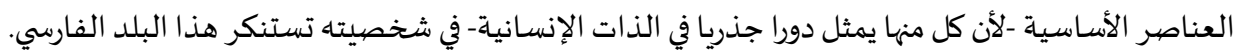

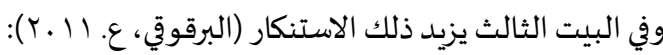

$$
\text { مَلاعِبُ جِنَّةٍ لَو سـارَفيها }
$$

أو إن نبرة البيت تتحول من الاستنكار إلى الاستهزاء أو الاستفزاز، حيث يقول إن لغتهم بعيدة عن الإفهام كل البعد حتى لو لو

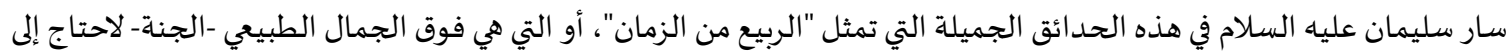

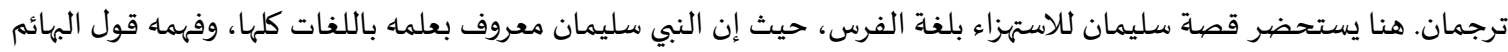

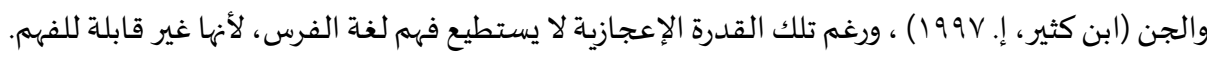
بعد ذلك يرجع إلى مدح شعب بوان مجددا، فيرسم لنا صورة عن جمال أشجارها وثمارها (الأبيات بين ه-9)، لكن هذا الثراء الثناء

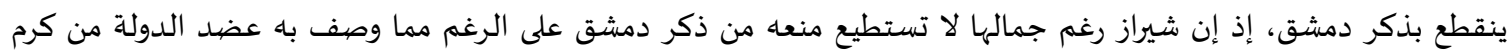

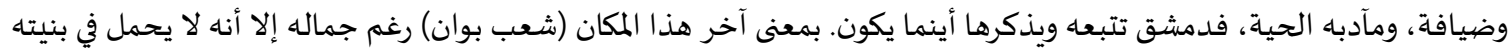

$$
\begin{aligned}
& \text { لَبيقُ الثُرِدِ صِينِيُّ الجِفانِ }
\end{aligned}
$$

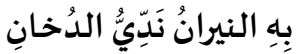

$$
\begin{aligned}
& \text { وَتَرحَلُ مِنهُ عَنَ قَلَبِ جَبَانِ } \\
& \text { يُشَيَّعُني إِلى النِوبَنَذَجانِ }
\end{aligned}
$$

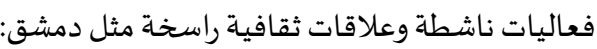

$$
\begin{aligned}
& \text { وَلَكو كانَتَ دِمَشَقَ نَنَى عِنَاني } \\
& \text { يَلَنجوجِيُّ ما رُفِعَتَ لِضَيَيفٍ } \\
& \text { تَحِلُّ بِهِ عَلَى قَلَبِ شُجِاعِ }
\end{aligned}
$$

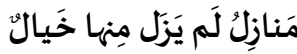

ولم يكتف المتنبي بكل هذا، إذ يقارن صوت الحمام بصوت الجارية المفنية، فكلاهما متفقان بالصيوت الإيقاعي، وأصهل أهل

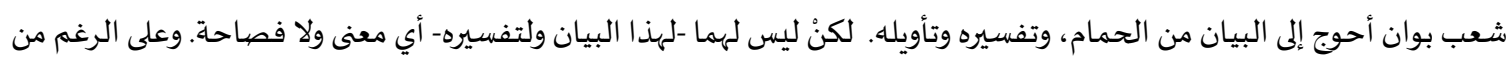

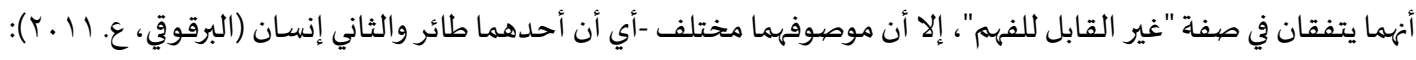

$$
\text { أَجابَتَهُ أَغانِيُّ القِيانِ }
$$

إذا غَنّى الحَمَامُ الوُرقُ فيها 


\section{إذاذا غَنّى وَنَاحَ إِلى البَيَانِ

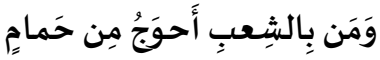

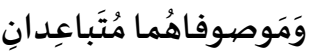

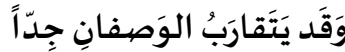

في الحقيقة بهذا الأسلوب الساخر ينقد المتنبي التفكير الفارسي الذي يعتبر الطيور مصدر العرفان والمعرفة. هنا يجدر ذكر -

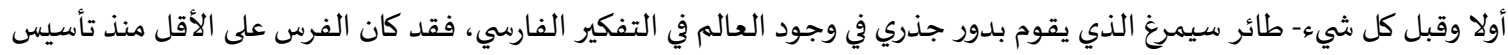

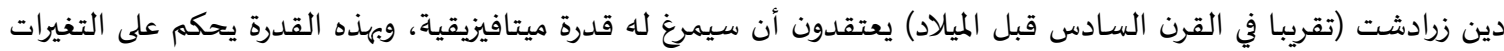

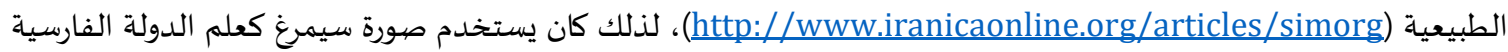

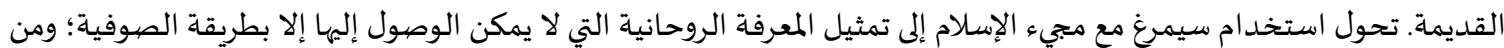

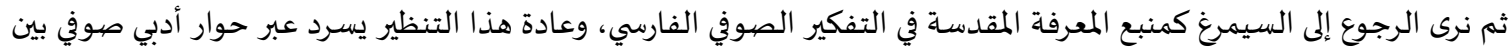

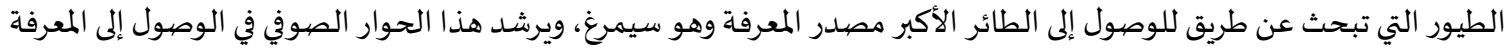

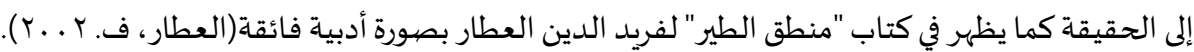

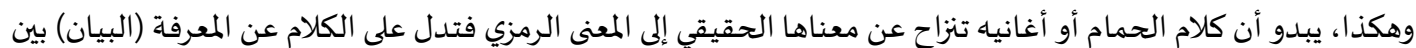

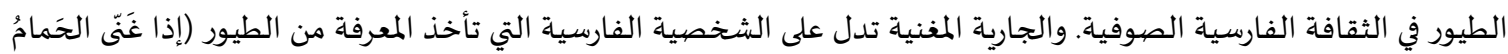

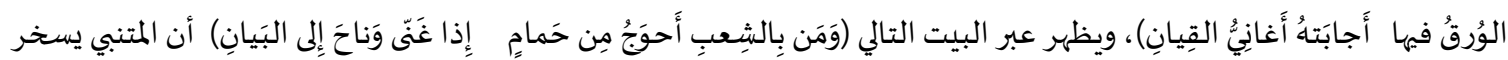

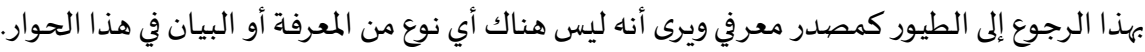

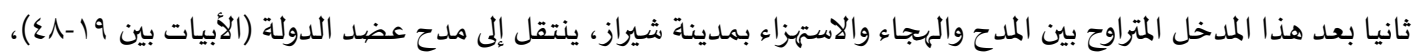

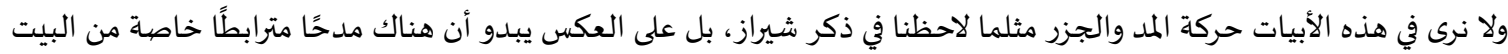

$$
\begin{aligned}
& \text { سَلَوتُ عَنِ العِبادِ وَذا المُكانِ }
\end{aligned}
$$

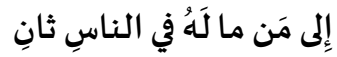

$$
\begin{aligned}
& \text { كَتَعليمِ الطَرادِ بِلا سِنَانِ }
\end{aligned}
$$

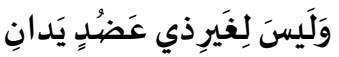

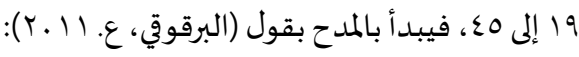

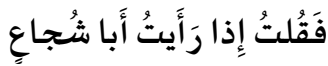

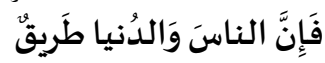

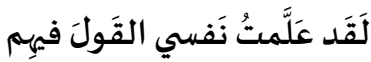

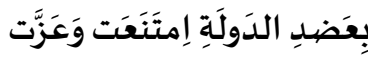

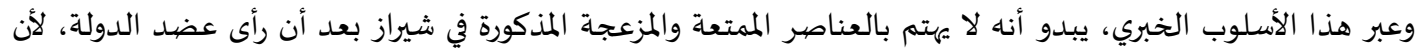

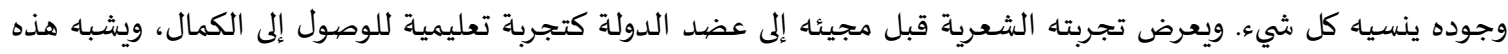

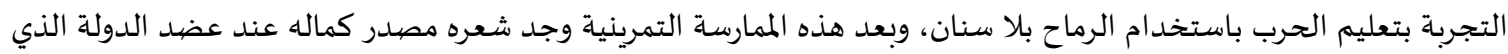
عزت به الدولة البويهية.

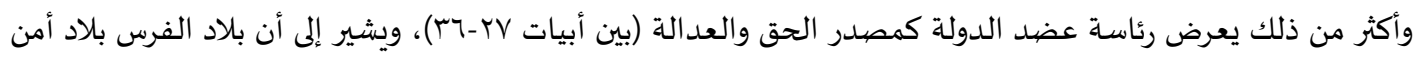

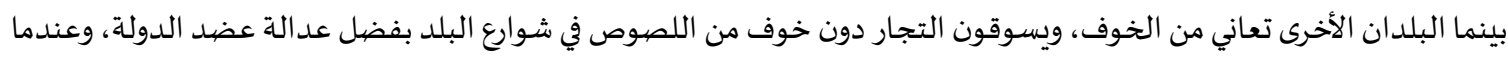

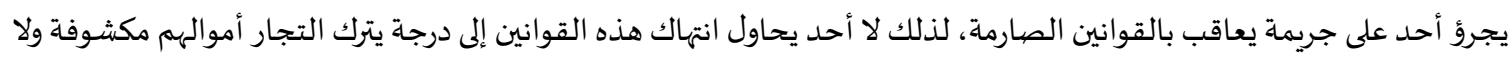

$$
\begin{aligned}
& \text { وَأَرضُ أَبي شُجَاعِعِن مِنَ أَمانِ } \\
& \text { وَتَضْمَنُ لِلِصَوَارِِِ كُلَّ جاني } \\
& \text { دُفِعِنَ إِلى المَحَحاني وَالرِعِانِ } \\
& \text { تَصيحُ بِمَن يَمُرَُُأَما تَر اني }
\end{aligned}
$$

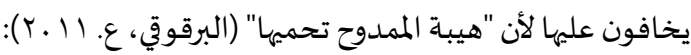

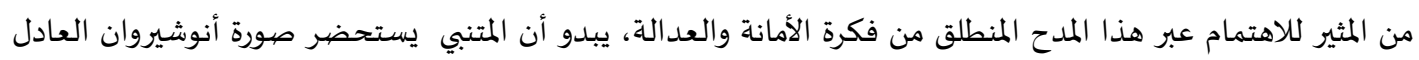

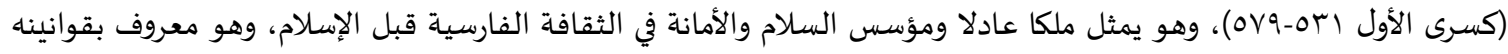

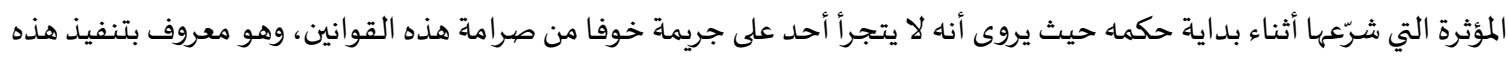

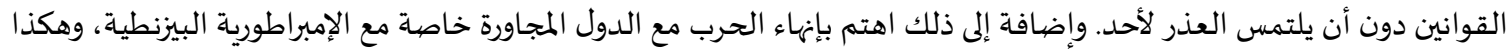

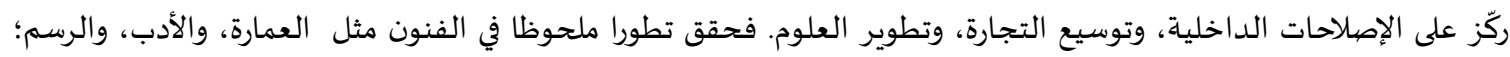

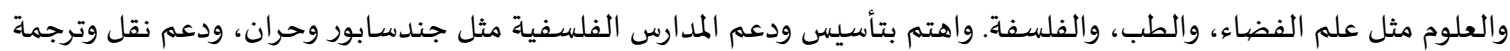

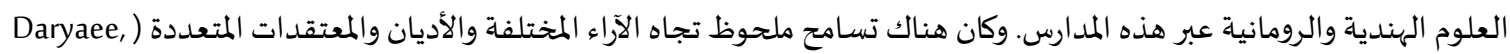


والهام. (T. 2009 من أجل كل هذا يعتبر عهده العصر الذهبي الثاني للدولة الساسانية، ويقوم بدور مثالي في تأسيس العدالة، والأمانة، والسلام، وقدرة ووحدة الثقافة الفارسية.

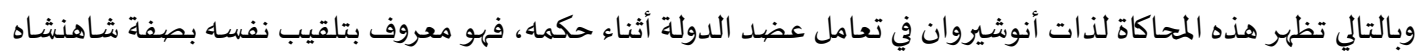

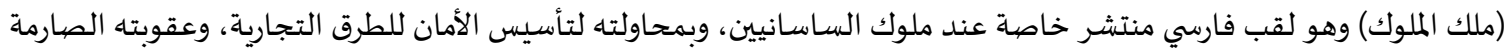

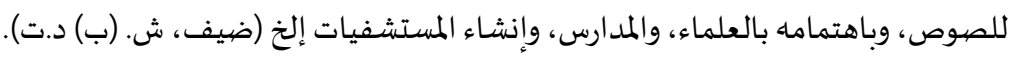

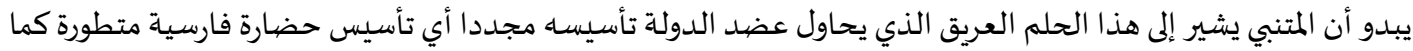

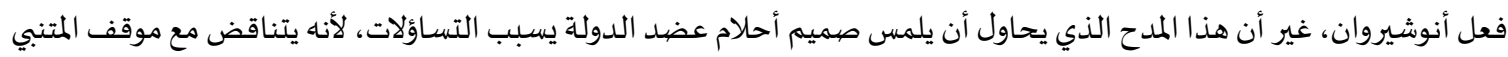

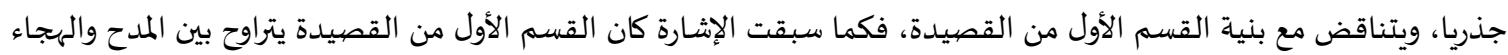

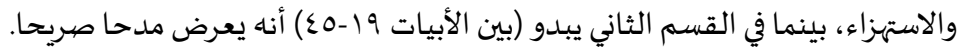

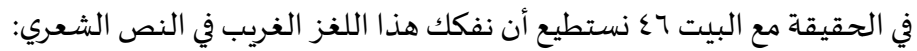

\section{يُوَّديّهِ الجَنانُ إلى الجَنانِ}

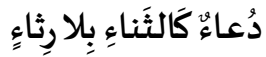

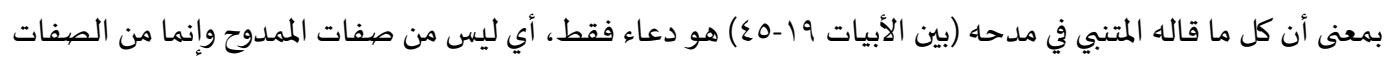

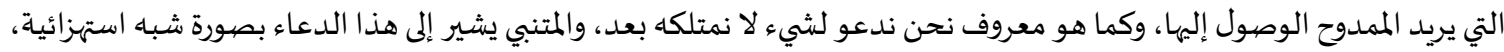

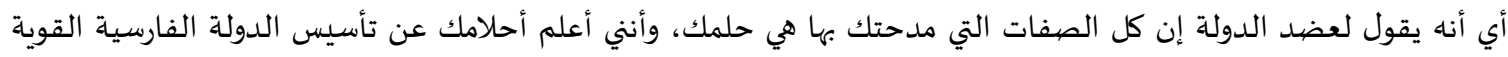

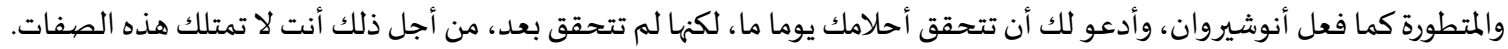

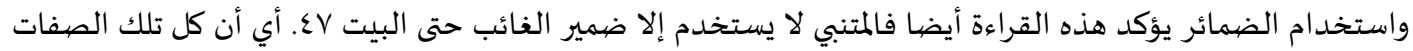

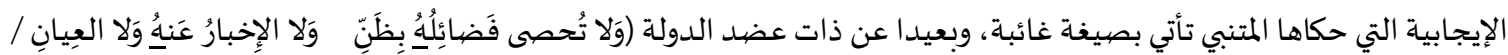

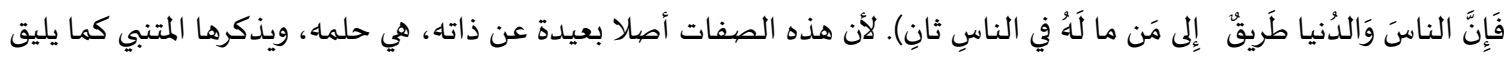

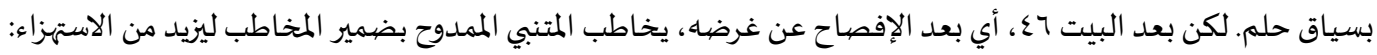

$$
\begin{aligned}
& \text { وَأَصَبَحَ مِنكَ فِي عَضِبِ يَمَانِ } \\
& \text { هُراءً كَالكَلامِ بِلا مَعَاني }
\end{aligned}
$$

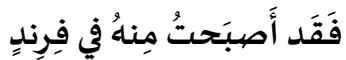

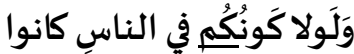

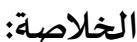

لقد بدا -في هذه الورقة البحثية- أن هناك موقفين متعارضين في مدح سيف الدولة وعضد الدولة انطلاقا من المقارنة بين قراءة القصيدة الميمية والنونية للمتنبي. إذ كما سبقت الإشارة، في مدح سيف الدولة تمتزج ذات المتنبي وطموحاته للمستقبل مع ذات سيف الدولة، وذلك ليس بسبب المحبة بينها فقط وإنما بسبب التفكير الأيديولوجي الذي يتمركز حول العصبية العربية، وتلك العصبية مرتبطة بالظروف التاريخية والسياسية التي تسبب تدهور الخلافة العباسية.

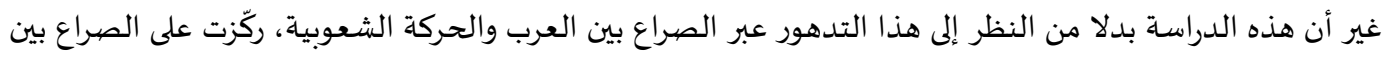

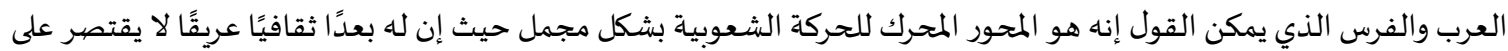

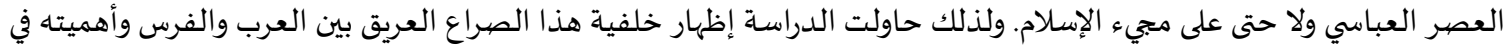

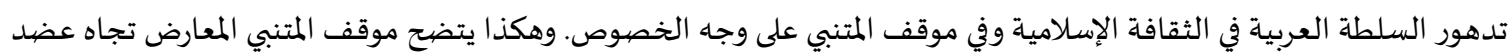
الدولة في القصيدة النونية، فهو أمير الدولة البويهية التي تمثل محاولة تأسيس الدولة الفارسية والاستيلاء على الثقافة الإسلامية

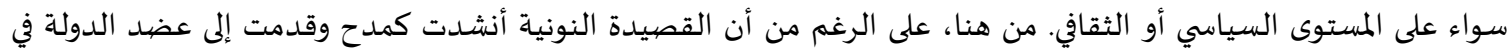

سماطاه، إلا أنها تتراوح بين المدح والهجاء والاستهزاء لإبراز موقف المتنبي المعارض لتلك المحاولة تحت صورة فنية شبه غامضية.

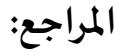

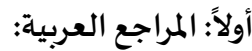

ا.. ابن الأثير، أبو الحسن العربه: علي ... ابن عبد الواحد الشيباني المعروف بابن الأثير الجزري، (.ب7 هـ) الكامل في التاريخ، لم، تحقيق:

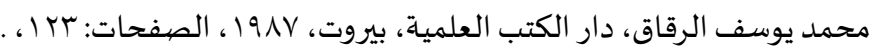

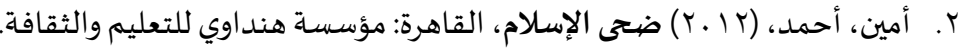




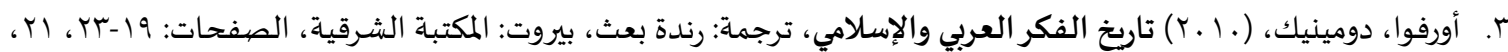
rO ، TO-YE, TH-YI, rT

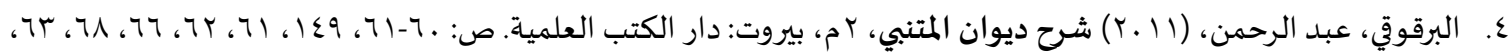
.77 ، 70 ، 78

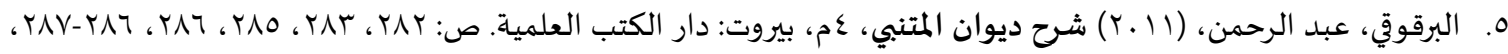
. TM

7. الجابري، محمد عابد، (ع ا ـr) نقد العقل العربي (1): تكوين العقل العربي، بيروت: مركز دراسات الوحدة العربية. ص: 79.

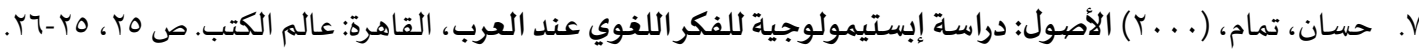

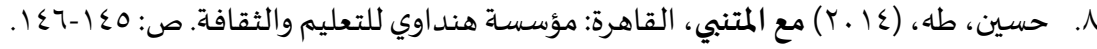

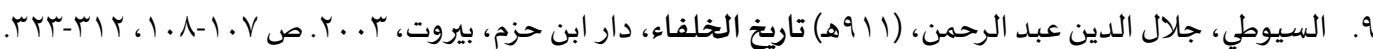

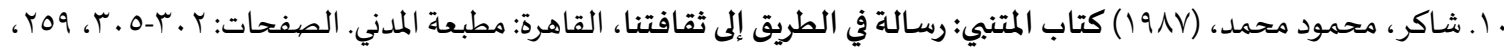

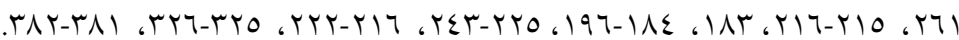
11. ضيف، شوقي، (د.ت.) تاريخ الأدبي العربي 0 عصر الدول والإمارات: الجزيرة العربية - العراق - إيران، القاهرة: دار المعارف. ص TrO-rTE، TrE-rTr

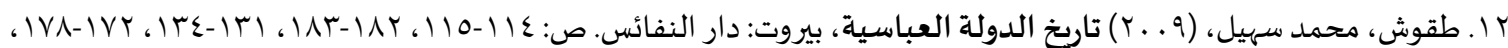
rII-r|

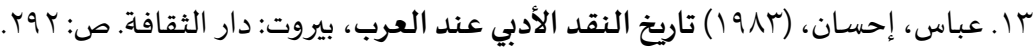

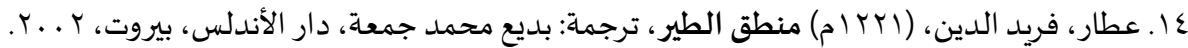

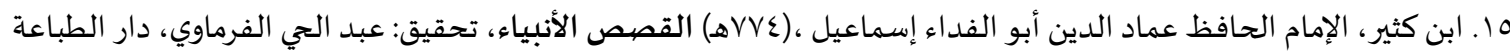

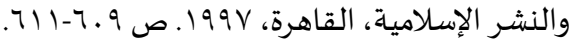
7 ا ـ ابن الكلبي، أبو المنذر هشام بن محمد بن السايب، (ع . rهـ) كتاب الأصنام، تحقيق: أحمد زكي باشـا، دار الكتب المصرية،

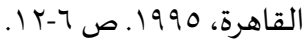

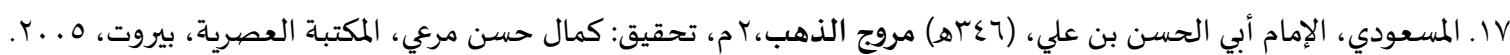
.910

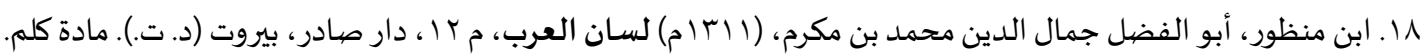
ثانياً: المراجع الأجنبية:

[1] Daryaee. Touraj, Sasanian Persia: The Rise and Fall of an Empire, London: I. B. Tauris, (2009), pp. 28-30.

[2] Ferdowsi, Epic Of Kings or Shahname, trans: Helen Zimmern, Ames: Omphaloskespis, (2000)

[3] Nissen. Hans J. \& Heine. Peter, From Mesopotamia to Irak: A Concise History, Chicago: The University of Chicago Press, (2009), pp.107-129, 125-131.

[4] Van De Mieerop, Marc, Philosophy Before The Greeks: The Pursuit of Truth in Ancient Babylonia, New Jersey: Princeton University Press, (2016), pp. 87-140.

[5] http://www.iranicaonline.org/articles/simorg. 


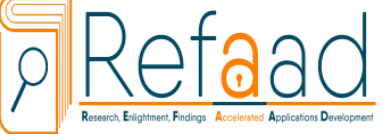

رفاد للدراسات والأبحاث www.refaad.com
المجلة الدولية للدراسات اللغوية والأدبية العربية

e-ISSN 2663-5860, p-ISSN 2663-5852

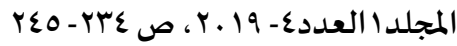

https://doi.org/DOI:10.31559/JALLS2019.1.4.3

\title{
Cultural Conflict in Al-Mutanabbi's Poetry The Case of Praising of the Sayf Al Dawlah and Adud Al Dawlah
}

\author{
Khayriye Kırtay \\ Turkish Researcher, PHD Student at The University of Jordan, Jordan \\ eledven@gmail.com
}

Received Date: 30/11/2019

Accepted Date: $24 / 12 / 2019$

Abstract. This study addresses the concept of cultural conflict in Al-Mutanabbi's poetry, and rather than picturing it based on the point of view of Arab and Shu'ubiyya conflicts, it will be picturing it as a conflict based on the Arab and Persian cultures. As it has a deep-rooted cultural dimension that isn't limited to the $4^{\text {th }}$ century $\mathrm{AH}$ nor the beginning of Islam only, and has a strong role in establishing the Islamic culture.

To analyze this hypothesis, the study will focus on the following: First the historical background for this conflict, the reason for this is to explain how the Shu'biyya movement revolves around this subject in general, on a cultural level. Second, compares between the "poem of Memyah" in which Al-Mutanabbi praised Saif Al-Dawlah through his importance in the hope of creating the strong Arab country in Al-Mutanabbi's eyes, and the "poem of Nonyah" in which he praised Adud AlDawlah, who represents the attempt of canceling the Arabic authority in Islamic culture. And Third, the study aims to point out Al-Mutanabbi's awareness regarding this rooted conflict between the two cultures by comparing between the two poems, alongside the importance of the historical conditions which announced the deterioration of the Abbasid Caliphate in the $4^{\text {th }}$ century $\mathrm{AH}$, which affected the formation of this awareness and the way it shows both in poetry and politics.

Keywords: Cultural conflict at the Abbasid era; Arabs and Shu'ubiyya; politics and Al-Mutanabbi's poetry.

\section{References:}

[1] 'bạs. Âhsạn, Tạrykh Ạlnqd Ạlạ̉dby 'nd Ạl'rb, Byrwt: Dạr Ạltḥqạfh, (1983), pp. 292.

[2] ț̣ar. Fryd Ạldyn, Mnțq Ạlțyr, Trjmü: Bdy` Mḥmd Jmª̈, Dạr Ạlạ̉ndls, Byrwt, 2002(1221m).

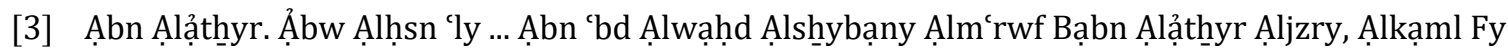
Altạrykh, 7m, Tḥqyq: Mḥmd Ywsf Ạlrqạq, Dạr Ạlktb Ạl'lmyh, Byrwt, 1987, (630 H),pp. 123 .

[4] Ạ̉myn. Ạ̉hmm, Ḍha Ạlạjslạm, Ạlqạhrh: Mw̉ssẗ Hndạwy Llt'lym Wạlthọạfh, (2012)

[5] Ảwrfwạ. Dwmynyk, Tạrykh Alfkr Al'crby Wạlạslạmy, Trjmë: Rnda B`th, Byrwt: Ạlmktbh Alshrquhh, (2010), pp.19-23, 21, 22, 21-23, 24-25, 25.

[6] Ạlbrqwqy. 'bd Ạlrḥmn, Sh̆rḥ Dywạn Ạlmtnby, 2m, Byrwt: Dạr Ạlktb Ạll'lmyh, (2011), pp.60-61, $149,61,62,66,68,63,64,65,66$.

[7] Albrqwqy. 'bd Alrḥmn, Shrh Dywạn Ạlmtnby, 4m, Byrwt: Dạr Ạlktb Ạl'lmyh, (2011), pp. 282, 283, 285, 286, 286-287, 288.

[8] Daryaee. Touraj, Sasanian Persia: The Rise and Fall of an Empire, London: I. B. Tauris, (2009), pp. 28-30.

[9] Ḍyf. Shwwqy, Tạrykh Ạlạ̉dby Ạl'rby 5 ‘ṣr Ạldwl Wạlạiạaạt: Ạljzyrh Ạl'rbyh- Ạl'rạq- Ásyrạn, Dạr Ạlm‘ạrf, pp. 233-234, 234-235.

[10] Ferdowsi, Epic Of Kings or Shahname, trans: Helen Zimmern, Ames: Omphaloskespis, (2000) 
[11] Ḥsạn. Tmạm, Ạlạ̉șwl: Drạsẗ A̧BBstymwlwjyẗ Llfkr Ạllghwwy 'nd Ạl'rb, Ạlqạhrẗ: 'ạlm Ạlktb,(2000), pp. 25, 25-26.

[12] Ḥsyn. Ṭh, M`ạlmtnby, Ạlqạhrh: Mw̉ssë Hndạwy Llt'lym Wạlthِqạfh, (2014), pp. 145-146

[13] Ạljạbry. Mḥmd 'ạbd, Nqd Ạl'ql Ạl'rby (1): Tkwyn Ạl'ql Ạl'rby, Byrwt: Mrkz Drạsạt Ạlwḥhh Al'rbyh, (2014), pp. 69.

[14] Ạbn Ạlklby. Ạ̉bw Ạlmndhrr Hshạm Bn Mḥmd Bn Ạlsạyb, Ktạb Ạlạ̉ṣnạm, Tḥqyq: Ạ̉ḥmd Zky Bạshạa, Dạr Ạlktb Ạlmșryh, Alqạhrh, 1995(204h), pp.6-12.

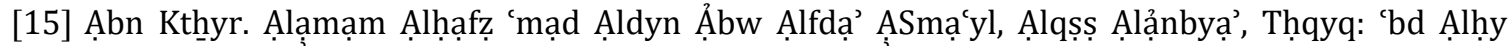
Ạlfrmạwy, Dạr Ạlțbạ đ̈ Wạlnshr Ạlạslạmyh, Ạlqạhrh, 1997(774h), pp. 609-611.

[16] Ạbn Mnẓwr. Ạ̉bw Ạlfụl Jmạl Ạldyn Mḥmd Bn Mkrm, Lsạn Ạl'rrb, M 12, Dạr Ṣạdr, Byrwt, Mạdẗ Klm, (1311m)

[17] Ạlms'wdy. Alamạm Ạ̉by Ạlḥsn Bn 'ly, Mrwj Ạldh̄hb,2m, Tḥqyq: Kmạl Ḥsn Mrcy, Ạlmktbh Ạl'ṣryh, Byrwt, 2005(346h), pp.98.

[18] Nissen. Hans J. \& Heine. Peter, From Mesopotamia to Irak: A Concise History, Chicago: The University of Chicago Press, (2009), pp.107-129, 125-131.

[19] Shạkr. Mḥmwd Mḥmd, Ktạb Ạlmtnby: Rsạlẗ Fy Ạlțryq Ala Thquạtnạ, Ạlqạhrh: Mṭb đ̣̈ Ạlmdny. (1987), pp. 302-305, 259, 261, 215-216, 183, 184-196, 225-243, 216-222, 325-326, 381-382.

[20] Ạlsywțy. Jlạl Ạldyn 'bd Ạlrḥmn, Tạrykh Ạlkhlfạ’, Dạr Ạbn Ḥzm, Byrwt, 2003, (911h), pp. 107108, 312-323.

[21] Ṭqwsh. Mḥmd Shyl, Tạrykh Ạldwlh Ạl'bạsyh, Byrwt: Dạr Ạlnfậss, (2009),pp. 114-115, 182-183, 131-134, 172-178, 310-311.

[22] Van De Mieerop, Marc, Philosophy Before The Greeks: The Pursuit of Truth in Ancient Babylonia, New Jersey: Princeton University Press, (2016), pp. 87-140. 